\title{
IMPORTÂNCIA DA MOTIVAÇÃO NO AMBITO DAS ORGANIZAÇÕES
}

\author{
Maura Sousa da Silva ${ }^{1}$ \\ Francinaldo Soares de Paula ${ }^{2}$
}

\begin{abstract}
RESUMO: O presente artigo tem como objetivo buscar demonstrar a importância da motivação no desenvolvimento organizacional, mostrando de que forma ela pode contribuir para o bom desempenho dos funcionários. Demonstra também as diferentes interpretações que há em torno do assunto proposto, e de que forma, realmente, a motivação acontece e como as empresas devem tratar seus colaboradores a fim de mantê-los motivados. As idéias expostas foram sustentadas através de revisão das literaturas existentes sobre o tema. $\mathrm{O}$ artigo é de grande importância para gestores e estudantes, pois leva ao entendimento que a falta de motivação no grupo de trabalho reflete no desempenho dos funcionários.
\end{abstract}

Palavras-chaves: motivação; organização; objetivos.

ABSTRACT: This paper aims seek to demonstrate the importance of motivation in organizational development, showing how it can contribute to the good performance of employees. It also demonstrates that there are different views about the subject proposed, and how motivation really happens, and how companies should treat their employees to keep them motivated. The ideas expressed were sustained through a review of existing literature on the subject. The article is of great importance for managers and students, because it leads to the understanding that the lack of motivation in the work group reflects the performance of employees.

Keywords: motivation, organization, goals.

\footnotetext{
${ }^{1}$ Docente do Curso de Adminstração da Facer - Unidade de Rubiataba.

Contato: professoramaura@live.com

${ }^{2}$ Docente do Curso de Administração da Facer - Unidade de Rubiataba.

Contato: professorfrancinaldo@live.com
} 


\section{INTRODUÇÃO}

A ciência da Administração tem desenvolvido inúmeras técnicas que têm colaborado para o aumento da eficiência das organizações, no sentido de conseguir o máximo de eficiência em todas as suas áreas.

No decorrer dos tempos as pessoas foram se tornando cada vez mais importantes para as organizações, passaram a ser vistas como fator determinante para o sucesso empresarial, pois são elas que, de fato, movem a empresa. Dessa maneira as organizações buscam, a cada dia, desenvolver novos meios que possam possibilitar, ou quiçá, garantir o condicionamento da produtividade dessas pessoas, e a motivação pode ser compreendida como sendo um dos principais elementos deste condicionamento.

Dentro deste contexto, torna-se pertinente compreender, de maneira científica, como a motivação dos funcionários pode auxiliar as empresas no alcance de seus objetivos, de forma a ajudar os administradores na gestão das empresas públicas e privadas a entender melhor o conceito da importância da motivação, para que possam implantá-la em suas organizações visando alcançar o máximo de eficiência possível no que diz respeito aos seus colaboradores.

\section{"SOBRE O TÍTULO"}

As pessoas, no atual ambiente econômico caracterizado pela concorrência cada vez mais acirrada e a busca de diferencial competitivo, devem ser cada vez mais valorizados para que se obtenha o máximo de eficiência e os melhores resultados, pois são os colaboradores que irão definir o rumo da empresa, é preciso dispor de um quadro de profissionais bem motivados para prestarem um serviço de qualidade.

Porém, Bergamini (1997) diz que a motivação varia de pessoa por pessoa, quando as empresas não dão a devida importância a esse fato os funcionários apresentam um baixo desempenho.

Chiavenato (2002) diz que o primeiro passo para compreender o que move o desempenho dos colaboradores na organização é compreender o que estes representam para a organização e o que pode motivá-los, pois nenhum funcionário produz se não estiver motivado e nenhuma empresa conseguirá alcançar seus objetivos e ter sucesso sem a colaboração e produção de cada um de seus colaboradores.

Na busca desse entendimento é pertinente compreender que não existem organizações sem pessoas, pois são as pessoas que vão movimentar tudo o que está envolvido no processo organizacional, nem mesmo a tecnologia, por mais avançada que seja não pode manter uma empresa sozinha, assim, toda organização é basicamente constituída de pessoas.

De acordo com Chiavenato (2003, p.80) para se estudar e entender o comportamento das pessoas em uma empresa o especialista em "recursos humanos (RH) tem duas alternativas: considerar as pessoas como pessoas ou considerar as pessoas como recursos". $\mathrm{Na}$ gestão moderna é necessário que se trate as pessoas como pessoas, ou seja, indivíduos dotados de personalidade e individualidades, e não meramente como meios de produção como já foram vistas ao longo dos anos. Ver as pessoas como simples recursos, por si só já é um fato que irá desmotivá-los, pois não é dada a eles sua devida importância. 
Nessa linha de raciocínio Bergamini (1997) diz que os trabalhadores são vistos como possuidores de diferentes habilidades e talentos pessoais que são próprios a um único indivíduo. Portanto, cada um deles terá condições de contribuir de maneira diferente para a consecução dos objetivos organizacionais.

As pessoas apresentam profundas diferenças, cada pessoa tem sua personalidade, sua cultura, conhecimentos e habilidades, e são essas particularidades que tornam cada uma delas importante para a organização, pois podem contribuir de diferentes maneiras para o sucesso empresarial (BERGAMINI, 1997).

Como cada pessoa é única e possuem suas particularidades a motivação de cada uma delas pode partir de algo diferente, é necessário saber trabalhar a motivação para conseguir atingir, mesmo que de diferentes maneiras, todos os funcionários da empresa.

O desempenho de cada pessoa está relacionado com as características individuais de cada um, porém, o bom desempenho requer muito mais do que simplesmente aptidões e habilidades, requer também motivação para trabalhar, o bom desempenho depende do grau de motivação que se encontra o empregado (BERGAMINI, 1997).

Para Chiavenato (2002, p.171) "a motivação pode ser conceituada como o esforço e a tenacidade exercidos pela pessoa para fazer algo ou alcançar algo. A motivação é um dos inúmeros fatores que contribuem para o bom desempenho no trabalho". O autor ainda afirma que "a motivação pelo fato de fazer parte internamente de cada indivíduo está sujeita a condições capazes de provocar mudanças originadas externamente de cada pessoa, ou pelas suas atividades realizadas na organização". (CHIAVENATO, 1994, p.166)

Para se compreender as pessoas e o comportamento humano é necessário conhecer o que a motiva, e se essa motivação é provocada por um estímulo provindo do ambiente (extrínseco) ou gerado no interior do indivíduo (intrínseco).

\footnotetext{
Para motivar seus empregados é preciso que você lhes passe pessoalmente mensagens inspiradoras e seja coerente ao fazer isso. E você deve usar qualquer outro recurso que ajude a desenvolver neles uma atitude positiva; alguns desses recursos são programas destinados a ajudá-los a melhorar sua educação, programas liberais d férias e folgas, bonificação em função de desempenho, festas e jantares que são apreciados por sua natureza socializante (GRIFFIN, 1996, p.105).
}

Um funcionário motivado irá produzir muito mais que um desmotivado, pois estará realizando suas tarefas com satisfação e dedicação, mantendo seu bom desempenho, já o desmotivado vê tudo como uma tortura e não faz nada por prazer, só o fazer por fazer, é do ser humano "se dedicar mais ao que te proporciona satisfação" (BERGAMINI, 1997).

Griffim (1996) propõe em seus estudos que o fracasso da maioria de nossas empresas não está na falta de conhecimento técnico. E sim, na maneira de lidar com as pessoas. É comum por parte dos administradores acharem que seus colaboradores não produzem com qualidade por falta de conhecimento, na verdade, isso pode estar ocorrendo devido a forma como esses colaboradores são tratados pela administração da empresa, a maneira com que a pessoa é vista e tratada influencia diretamente na sua forma de trabalhar. 
Dentro de cada indivíduo existem desejos, razões, objetivos, querer alguma coisa que vá lhe dar satisfação. É importante também que a organização procure criar um acordo, de forma que as capacidades do trabalhador e as demandas do cargo estejam em equilíbrio para que os resultados possam ser compensadores, tanto para o trabalhador quanto para a empresa (CHIAVENATO, 2002, p.171).

De acordo com Bergamini (1997) a motivação cobre grande variedade de formas comportamentais. A diversidade de interesses percebida entre os indivíduos permite aceitar, de forma razoavelmente clara, que as pessoas não fazem as mesmas coisas pelas mesmas razões. O estudo da motivação abrange, em última análise, aquelas tentativas de conhecer como o comportamento é iniciado, persiste e termina. Ainda Bergamini (2003) afirma que não há nada mais desmotivador do que tentar motivar alguém, um dos erros mais comuns que existe é o fato de que os gerentes tem a responsabilidade de motivar o quadro de funcionários das empresas. O processo de motivação é sempre intimo e pessoal. É essencial entender o sentido que cada um atribui ao trabalho que realiza ao invés de explicações comuns que generaliza todo individuo.

Pode-se perceber através da afirmação desses autores e do próprio convívio com as pessoas que a motivação é algo intrínseco, ou seja, ninguém motiva ninguém, e a pessoa que motiva a si próprio. Dessa forma cabe à organização oferecer as pessoas fatores que possam levá-las a se sentir motivadas e evitar causar o objetivo contrário, dar motivos para que o funcionário se sinta desmotivado.

Para Chiavenato (1994) a motivação para o trabalho é um aspecto que interfere no processo de relações humanas, produtividade e qualidade de vida, o que pode influenciar na qualidade dos serviços oferecidos na empresa. Funcionários motivados podem trazer uma serie de benefícios organizacionais, como maior produtividade e vendas, mas a falta de motivação dos mesmos pode levar a empresa a ter várias consequências negativas, como baixa produtividade e visão negativa da mesma. Pode até mesmo a empresa, após um período em que a motivação não é trabalhada ou introduzida de forma adequada no ambiente da organização, ser levada a uma possível ruína. Como afirma Glasser (1994, p.15) apud Bergamini (1997, p. 35) onde relata que "o fracasso da maioria de nossas empresas não está na falta de conhecimento técnico, e, sim na maneira de lidar com as pessoas".

As empresas precisam de funcionários motivados, além disso, as pessoas tratam-se do capital mais importante das empresas, para sustentar essa idéia citamos Bergamini (1997) que afirma em seus estudos que as pessoas estão se tornando cada vez mais destaque nesses ambientes organizacionais. No papel do gestor empresarial torna-se necessário a habilidade de lidar com as diferenças de cada indivíduo, aceitá-las e trabalhá-las em prol da empresa.

\section{CONSIDERAÇÕES}

Através do estudo pode-se perceber que as organizações muitas vezes não estão dando a devida importância a motivação de seus funcionários, ou em não interessarem-se em atender as necessidades individuais de seu quadro de colaboradores. 
Esses acontecimentos consequentemente atrapalham no desenvolvimento empresarial e levam as empresas a trabalharem os fatores que promovem a motivação dos mesmos ou até mesmo melhorar a forma que vem trabalhando a motivação em seu âmbito organizacional.

Tais atitudes se devem a importância da motivação dos funcionários para garantir o bom desempenho dos mesmos, e assim o alcance dos objetivos organizacionais. Para que a organização tenha sucesso, é necessária a satisfação, e consequentemente o sucesso individual de cada um de seus colaboradores, pois são eles que vão determinar o futuro da organização.

\section{REFERÊNCIAS}

BERGAMINI, Cecília Whitaker. Motivação nas organizações. $4^{\mathrm{a}}$ ed. São Paulo: Atlas, 1997.

CHIAVENATO, Idalberto. Recursos Humanos. $3^{a}$ ed. São Paulo: Atlas, 1994.

Gerenciando Pessoas: como transformar os gerentes em gestores de pessoas. $4^{\mathrm{a}}$ ed. São Paulo: Prentice Hall, 2002.

Administração de Recursos Humanos: Fundamentos Básicos. $5^{\text {a }}$ ed. São Paulo: Atlas, 2003.

GRIFFIN, Gerald R. Maquiavel na administração: como jogar e ganhar o jogo do poder na empresa. São Paulo: Atlas, 1996.

MEGGINSON, Leon C; MOSLEY, Donald C.; PIETRE JUNIOR, Paul H. Administração: conceitos e aplicações. São Paulo: Harbra, 1998. 